\title{
DE UNA DISONANCIA NO RESUELTA: MEDIDA Y PASIÓN \\ EN EL COMPENDIUMIMUSICAE
}

\author{
Carmen Pardo \\ (U. de Barcelona)
}

Naturaleza del sonido y variedad de las pasiones forman tal vez un acorde que resuena en la pregunta por la conexión entre el cuerpo, el espiritu y el sonido. Pero, en una obra que se inicia con el estudio de la medida, este acorde no puede por mas que aparecer como una disonancia no resuelta.

El compendio se abre asignando al sonido una finalidad: deleitar y provocar pasiones diversas, y enunciando que los medios para alcanzar este fin son sus propiedades: el liempo y la altura. El filósofo se atiene con ello a las dos coordenadas que son mensurables y que, ya en su época, con la generalización progresiva de la partitura, encuentran en ese espacio visual un trataniento adecuado a la formulación numérica.

Este punto de partida, que pareceria situar la cuestión de las pasiones en el ámbito puramente musical, es complementado por las consideraciones previas que el filósofo aporta. Unas consideraciones qua se convertirán en los presupuestos a partir de los cuales se exanninará las propiedades del sonido, y que seitalarán el umbral que distinguirá lo que es propianente musical, al tiempo que esbozarín el modelo perceptivo a seguir. En estas notas previas se expone que todos los sentidos son capaces de algún placer, ${ }^{1}$ pero que este placer requiere una cierta proporción del objeto con el sentido mismo; una proporción que va a permitir, por ejemplo, la distinción entre música y ruido. La proporción debe ser aritmélica y no geométrica. Se atiende de este modo, a una percepción que podriamos denominar analitica y que tiene por objeto la captación del orden entre las partes antes que la aprehensión de la totalidad, alejándose asi del modelo perceptivo clásico que hacía de la percepción musical captación de esa armonia superior heredada del pitagorismo y del neoplatonismo. ${ }^{2}$

Estas consideraciones se extienden a la percepción del objeto por parte del espíritu, ya que es aqui donde se va a producir la afirmación de lo agradable, lo que se podrín denominar la formulación de un juicio.

Con su obra, el filósofo ofrecerá la medida de esa proporción necesaria entre el espiritu. la música y el oido. Sin embargo, será justamente el estudio de las propiedades del sonido a partir de estas consideraciones, lo que evidenciará esa disonancia entre el modelo matemático propuesto y el efecto que el sonido produce: el movimiento de las pasiones.

Asi, respecto a la primera propiedad, el tiempo, se asiste a un tratamiento dual que partce derivarse de la influencia que éste opera sobre la imaginación y el cuerpo. Descartes realizará un análisis divergente ya que, en lo que concierne a la imaginación, primará la comprensión al establecer que el tiempo debe estar constituído por partes iguales o por partes que se encuentran en proporción doble o triple respecto a la unidad establecida como medida temporal. Además, para ajudar a la imaginación, el sonido inicial de cada medida -el liempo fuerte- - será marcado distintamente. Sin embargo, lo que se comprende con ello, parece mas bien el espacio que ocupa cl tiempo, su espacialización sea en la partitura o en la imaginación,

I R. Descantes, Compendio de misica. Tecnos, Madrid, 1992, (trad. de P. Flores y C. Ga!lardo), p. 57.

2 Con tstas consideraciones Descartes aporta un nuevo fundamento a la ciencia musical, aunqüte sus efectos Se sentirán más sobre el ḋmbito estítico qus sobre el sonoro. 
pero no la duración que impondria cl propio tiempo musical. En lo que se refiere al cuerpo se expone, aunque con cautela, la variedad de medidas musicales y la diversidad de pasiones que éstas pueden producir. Con ello se explicita el nexo que va desde el movimiento de los espiritus animales, al sentimiento que se produce y es asociado a este movimiento. Sin embargo, esta conexión con los sentimientos, no parece tan claramente derivada del movimiento sonoro en su correspondencia con Mersenne donde se refiere, con más intensidad que en el compendio,a la fuerza de la costumbre y se apunta quizá hacia una teoria asociacionista. ${ }^{3}$ En lo que concierne a la segunda propicdad del sonido: la altura, el estudio se lleva a cabo siguiendo también el modelo matemático y referiéndose a los efectos que el sonido produce. La desvinculación entre la simplicidad numérica como criterio del agrado, y el efecto que el sonido provoca, aparece aqui con el tratamiento de la disonancia y el análisis de los diferentes acordes, mostrando la dificultades que surgen al reconocer cualidades a las consonancias que responden a las pasiones. 4

De este modo, la falta de correspondencia entre la proporción matemática y su efecto, la alusión a la costumbre, a las ideas asociadas que se guardan en la memoria... no permiten establecer una posición firme respecto al movimiento de las pasiones, $y$ crean una red que impide la creación de un pensamiento que pueda afirmar la objetividad del juicio. Por ello, con más intensidad ahora, parece sonar esa disonancia que, en torno a este problema, acomparia al pensamiento cartesiano.

3 Carta del 18 de marzo de 1630 en Oeurres / hhilosophiques, 1,Garnier Frerres, 1963, textos establecidos por F. Alquis. Cfr. Compendio de misica, op. cit., p. 65.

4 Compendio de misica, op. cit.,p. 82. No obstante,esta postura no se mantiene acorde con la alirmación realizada en la misma página respecto a la consideración de que las terceras y sextas mayores son más agradables qué las menores. Cfr, tambión, Carta dal 4 de marzo de 1630 en Oeanres Philosophiques, op. cit. 